\title{
Retinal Pigment Epithelial Cells Produce Mitogenic Factors for Retinal Microvascular Cells in Culture: A Preliminary Report
}

\author{
H. C. WONG, M. E. BOULTON, P. CLARK, M. BAYLY and J. MARSHALL \\ London
}

\begin{abstract}
Summary
Conditioned media from human retinal pigment epithelial cells have been shown to have mitogenic activity for retinal microvascular cells in vitro. The conditioned media stimulated the proliferation of both bovine retinal capillary endothelial cells and pericytes.
\end{abstract}

It has been observed that when large numbers of retinal pigment epithelial (RPE) cells are destroyed by pan retinal ablation in proliferative diabetic retinopathy and subsequently replaced by migration and division there is a regression of neovascularisation at a site remote from photocoagulation. This finding has prompted us to investigate whether human RPE cells are capable of producing factors which affect the proliferative ability of retinal microvascular cells.

\section{Methods}

\section{(a) Cell Culture}

Human RPE cells were grown in Ham's F10 medium supplemented with 20 per cent fetal calf serum as described by Boulton et al. ${ }^{1}$ Bovine retinal capillary endothelial (BRCE) cells were grown on a gelatin substrate in Dulbecco's modified Eagle's medium (DMEM) plus 7.5 per cent human platelet poor plasma mixed with pericyte conditioned medium in $1: 1$ ratio; and supplemented with retinal crude extract, heparin and insulin. ${ }^{2}$

Bovine retinal pericytes and bovine tenon fibroblasts were grown in DMEM supplemented with 20 per cent fetal calf serum.

\section{(b) Production of conditioned medium}

Confluent cultures of RPE cells and fibroblasts between the second and sixth passage were used for the production of conditioned medium. RPE conditioned medium (RPE-CM) and bovine tenon fibroblast conditioned medium (BTF-CM) were prepared by washing cultures grown in $25 \mathrm{~cm}^{2}$ culture flasks twice with phosphate buffered saline. $8 \mathrm{ml}$ of fresh DMEM supplemented with 7.5 per cent human platelet poor plasma was added to each flask for 2 days to allow for conditioning. The conditioned medium was removed and stored at $-20^{\circ} \mathrm{C}$ for future use.

\section{(c) Mitogenic assays}

BRCE cells, pericytes and fibroblasts were plated in their respective growth media at $2 \times 10^{4}$ cells per $17 \mathrm{~mm}$ multiwell on day 0 . With respect to BRCE cells, multiwells were gelatinised to permit cell attachment. On day 1 , cells were detached with trypsin from a number of wells and an 'initial' cell count was made using a haemocytometer. In the remaining wells the media was changed and test media was added. This consisted of conditioned medium mixed with unconditioned DMEM supplemented with 7.5 per cent platelet poor plasma in a ratio of $1: 1$. Unconditioned medium acted as a control for any mitogenic response.

On day 4 a 'final' cell count was made on BRCE cells and fibroblasts. Since pericytes grew more slowly, an intermediate cell count was made on day 5 , and final cell count made on day 9 . All test media were tested on six wells in each experiment and repeated on two separate occasions.

From Institute of Ophthalmology, Judd Street, London.

Correspondence to: Professor J. Marshall, Institute of Ophthalmology, Judd St, London WC1H 9QS.

Presented at the Annual Congress of the Ophthalmological Society of the United Kingdom, April 1987. 

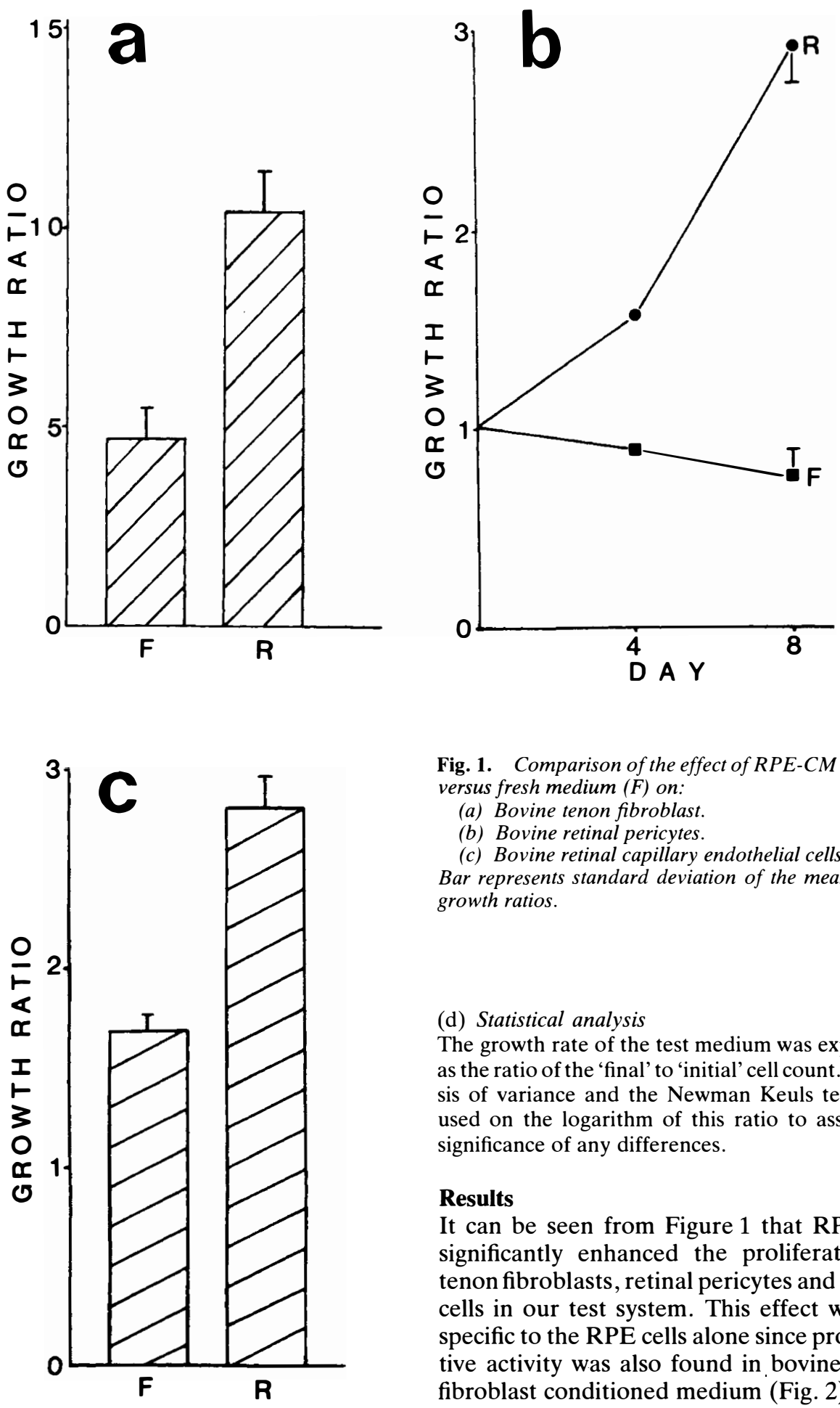

Fig. 1. Comparison of the effect of RPE-CM (R) versus fresh medium $(F)$ on:

(a) Bovine tenon fibroblast.

(b) Bovine retinal pericytes.

(c) Bovine retinal capillary endothelial cells.

Bar represents standard deviation of the mean of the growth ratios.

(d) Statistical analysis

The growth rate of the test medium was expressed as the ratio of the 'final' to 'initial' cell count. Analysis of variance and the Newman Keuls test were used on the logarithm of this ratio to assess the significance of any differences.

\section{Results}

It can be seen from Figure 1 that RPE-CM significantly enhanced the proliferation of tenon fibroblasts, retinal pericytes and BRCE cells in our test system. This effect was not specific to the RPE cells alone since proliferative activity was also found in bovine tenon fibroblast conditioned medium (Fig. 2). 


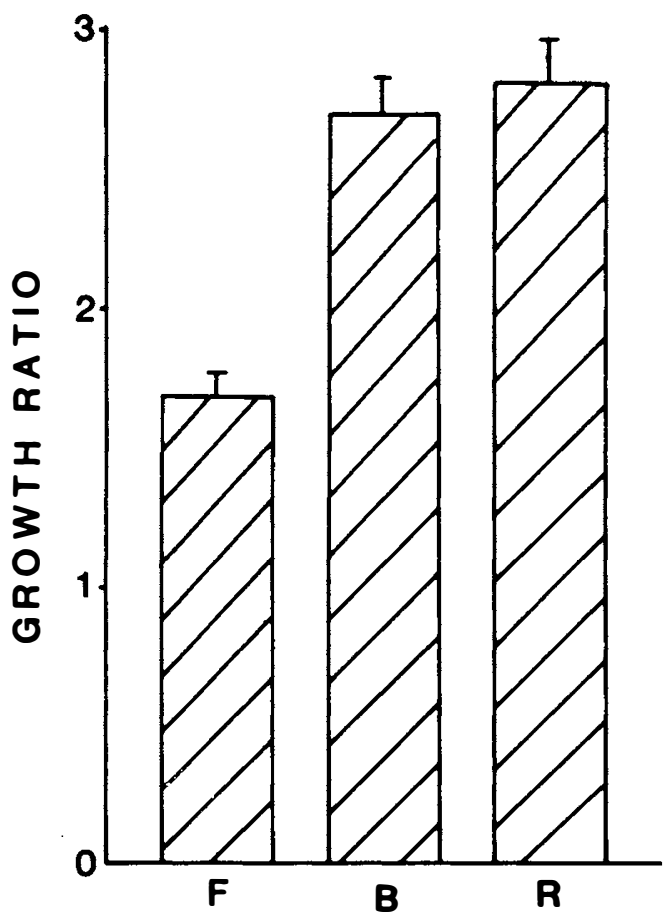

Fig. 2. Comparison of effect of RPE-CM $(R)$ versus tenon fibroblast conditioned medium $(B)$ and fresh medium $(F)$ as control on bovine RCEC.

\section{Discussion}

The observation that RPE cells produce a mitogenic factor(s) for microvascular cells in vitro is in keeping with the findings of Morse et al. ${ }^{3}$ and Connor et al. ${ }^{4}$ However the growth response was not exclusively seen in microvascular cells since bovine tenon fibroblasts were also stimulated to proliferate. It seems possible that the mitogenic factor will be identified as fibroblast growth factor (FGF) since Schweigerer et al. ${ }^{5}$ has demonstrated that
RPE cells are capable of producing FGF in vitro.

It should be remembered that this is an in vitro system, neovascularisation in vivo involves a number of steps including basement membrane breakdown, endothelial cell proliferation and migration. Thus care must be taken in relating these results to the in vivo pathophysiology. Whatever the interpretation, we have demonstrated that RPE cells do have the capability to modify the behaviour of retinal microvascular cells in vitro.

This study was supported by the Francis and Renee Hock Foundation, Moorfields Eye Hospital Endowments Fund, The Mason Medical Foundation, SmithKline and French, Lasertek Ltd and The Help the Hospital Charity. The authors are indebted to Mr. David Mcleod of the Surgical Vitreoretinal Unit of Moorfields Eye Hospital for his constant encouragement during this study; and to Mr. S. Rothery for technical assistance.

\section{References}

${ }^{1}$ Boulton ME, Marshall J, Mellerio J: Retinitis pigmentosa: a preliminary report on tissue culture studies of retinal pigment epithelial cells from eight affected human eyes. Exp Eye Res 1983, 37: 307-13.

${ }^{2}$ Wong HC, Boulton ME, Marshall J, Clark P: Growth of retinal capillary endothelia using pericyte conditioned medium. Invest Ophthalmol Vis Sci (in press).

${ }^{3}$ Morse LS, Sidikaro Y, Terrell J: Retinal pigment epithelium promotes proliferation of choroidal microvessels in vitro. Invest Ophthalmol and Vis Sci (Suppl) 1986, 27: 327.

${ }^{4}$ Connor T and Glaser BM: RPE cells can simultaneously release inhibitors and stimulators of endothelial cell proliferation. Invest Ophthalmol and Vis Sci (Suppl) 1987, 28: 203.

${ }^{5}$ Schweigerer L, Malerstein B, Neufeld G, Gospodarowicz D: Basic fibroblast growth factor is synthesized in cultured retinal pigment epithelial cells. Biochem Biophys Res Comm 1987, 143: 934. 